\title{
Identifying and Tracing Single Products During Their Entire Life Cycle Through Networked Manufacturing System
}

\author{
Saeed A. Mousa \\ Palestine Technical University, Tulkarm, Palestine
}

\begin{abstract}
This study covers the problem that most products become less competitive especially in the decline stages of their life cycle as most companies do not put adequate emphasis on using networked manufacturing systems in the entire life cycle of a single product. The study employed a non-experimental approach to collect data. The research paper relied on secondary data for further analysis. The secondary sources used in this paper have been referenced progressively in the entire paper. The paper found that most companies are often faced with the challenge of coping with quality management in a product life cycle. Also, it found that networked manufacturing systems have provided a new paradigm for real-time monitoring and control at various life stages. The paper is divided as following parts: section 1 is about the background and problem statement. Section 2 comes through literature review including theoretical \& empirical review. Section 3 explains the procedures and methods that were used in carrying out the study. It explains how data collection was carried out and how data analysis was performed. Section 4 is about the results the paper found. Section 5 is a discussion of the results presented.
\end{abstract}

Keywords: networked manufacturing, product life cycle, potential of market growth, industrial automation

\section{Introduction}

A networked manufacturing system is a program that electronically collects and distributes data from manufacturing processes. The system consists of business and manufacturing intelligence software that is vital for effective work management to realize optimal utilization of critical resources of production. Assuring reliability, safety, and quality of a product is an essential part of product development. Various companies normally address the aspect of product quality too late. Some companies employ disjoint processes with insufficient cross-functional communication (Quality Lifecycle Management, 2011). Carrying out manufacturing process without managing quality in an integrated manner in the entire life cycle of a product can be very costly to companies. Achieving quality of a product is a multidimensional concern for discrete manufacturers. Product quality is normally sacrificed in favor of profitability and globalization considering the increasing competition in the marketplace, an extensive network of suppliers and contractors, global workforce and technically complex products to deliver.

\section{Background Information}

There has been a major shift in the manufacturing of products, dating back to the post-World War II

Saeed A. Mousa, lecturer of Innovation at Palestine Technical University, Tulkarm, Palestine.

Correspondence concerning this article should be addressed to Saeed A. Mousa, Kadoorie University, Tulkarm, P.O. Box 7, Jaffa Street, Palestine. 
industrial setting (Zhuang \& Zhang, 2010). The setting led to a number of vertically integrated industries. The world economic structures today have evolved and changed various aspects of production designs. Various technologies have been put into use and have attained positive results in improving competitive advantage. Over the past years, there has been an increasing trend where companies focus on globalization and high value. The manufacturing system architecture has evolved from the traditional centralized model to the networked model which is the recent model (Jiang, Zhao, Zhang, \& Wang, 2008). The systems in the modern manufacturing industry are in networked frameworks through a wide range of networking systems that integrate the heterogeneous collection of manufacturing devices, equipment, and real-time information. The system carries out monitoring and control of manufacturing processes with the aim of maximizing the quality of services offered. Various companies have been using the system to control operations. From this perspective, the health data of a machine will reflect the health condition of the machine hence influencing the decision for networked manufacturing systems. The supervisory controllers in a manufacturing setup are also able to take preemptive measures aimed at ensuring continuous operations by executing fall back plans. The life story of several successful products is an account of their undergoing through some recognizable stages (Levitt, 2017). The figure below (Figure 1) illustrates the stages.

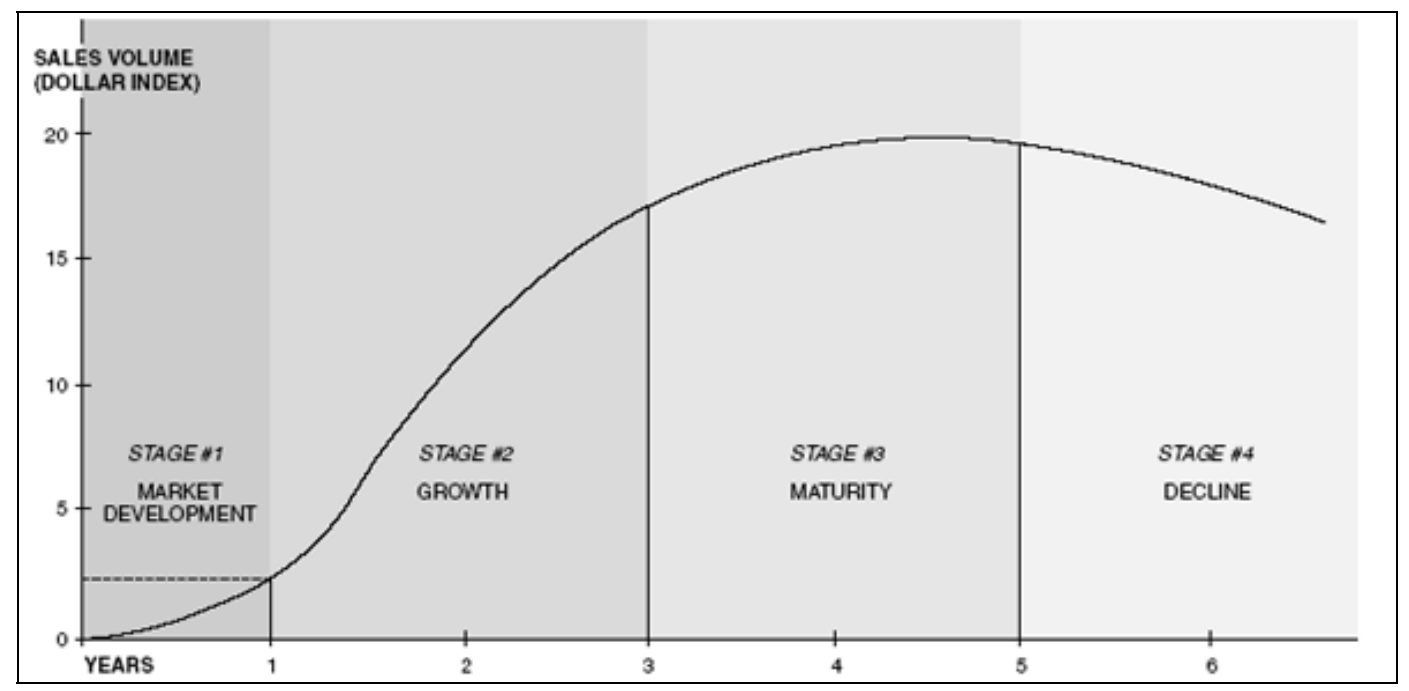

Figure 1. Product life cycle-historical pattern (Levitt, 2017).

\section{Problem Statement}

Most companies do not put adequate emphasis on using networked manufacturing systems in the entire life cycle of a single product. As a result of this, most products become less competitive especially in the decline stages of their life cycle (Brookins, 2017). It also gives the reason why certain products are outlived by other products which are attributed to failure to use such system. The technology, however, has been extensively utilized by companies for maintenance operations. The paper will explore the effectiveness of networked manufacturing system at the various stages of product life cycle.

\section{Literature Review}

\section{Theoretical Review}

Based on the topic of study, various theories can be used to relate the problem statement with the topic of 
study. Production theory brought forward by Robert Dorfman (2006) is one of the theories. The theory explains the principle that firms use the quantity of a product that they produce and sell both in the short run and in the long run. The quantity of the product will also depend on the current stage of the product in its life cycle. The theory also brings a mathematical expression of the quantity of product and other combination of factors to minimize cost. $y=f(x 1, x 2, \ldots, x n ; k 1, k 2, \ldots, k m)$ (Dorfman, 2006). Considering the topic of study, the networked manufacturing system can be used to determine these factors of production at every stage of the product's life cycle. The second theory is the network theory for robustness. The theory states that networked manufacturing systems translate manufacturing systems into network models, analyze them, and detect autonomous nature of fluctuations.

\section{Empirical Review}

Various researchers have put much effort in various disciplines of manufacturing systems such as quality management of product lifecycle among other subjects of study. However, little or no effort has been put to carry out research on the topic. Some of the researchers include Mirja Meyer who published her research titled “A Network Theory Approach for Robustness Measurement in Dynamic Manufacturing Systems”. Meyer (2013) argues that robustness is a vital element of manufacturing systems in a highly fluctuating environment. The fluctuations are often caused by changing user requirements, distractions in the supply chain and short-term changes in demand. Meyer concludes that for a company to remain profitable and competitive, the manufacturing system needs to display a robust performance.

Zheng and Chen (2005) also published an article titled "Secure strategy for networked manufacturing system”. The article states that manufacturing systems meet the high demand from customers, partners, suppliers, and other key players in the manufacturing industry. The systems offer a wide range of information as well as the collaboration of services. McFarlane and Sarma (2002) also conducted a research titled "The Intelligent Product in Manufacturing Control”. The authors focused on establishing a link between manufactured products and the internet by use of Auto ID technology. The authors found out that accurate and timely information about a given item to be used in control functions or decision-making is helpful in profiling an intelligent product. Such information can be useful in influencing better decisions concerning the destiny of the product (McFarlane \& Sarma, 2002). Based on the empirical review, it is clear that little or no study has been conducted on the topic. On the contrary, various studies such as the ones discussed above on the related subjects have been carried out by various authors.

\section{Methodology}

This section explains the procedures and methods that were used in carrying out the study. It explains how data collection was carried out and how data analysis was performed.

\section{Data Collection Techniques}

The study employed a non-experimental approach to collect data. The approach is normally applied in studies whose purpose is a description. The research paper relied on secondary data for further analysis. Secondary data, in this case, refer to various research papers, books, and other journal articles that are already published for reference. The secondary sources used in this paper have been referenced progressively in the entire paper. The research paper also employed a qualitative approach to obtain data for analysis. It implies that various opinions also had significant contributions to this research paper. The data or the information obtained 
from the study have been summarized for "better understanding" of the topic. Various figures have been used to give more insights on the subject matter.

\section{Results}

Networked manufacturing systems meet the high demand from customers, partners, suppliers, and other key players in the manufacturing industry. Most companies are often faced with the challenge of coping with quality management in a product life cycle (Product Life Cycle Stages, 2017). Various studies indicate that networked manufacturing system is one of the strategies of dealing with this challenge. Networked manufacturing systems have provided a new paradigm for real-time monitoring and control at various life stages. Networked manufacturing systems have demonstrated the greater potential of market growth as well as industrial automation. The figure below (Figure 2) is an illustration of the potential of the networked manufacturing system.

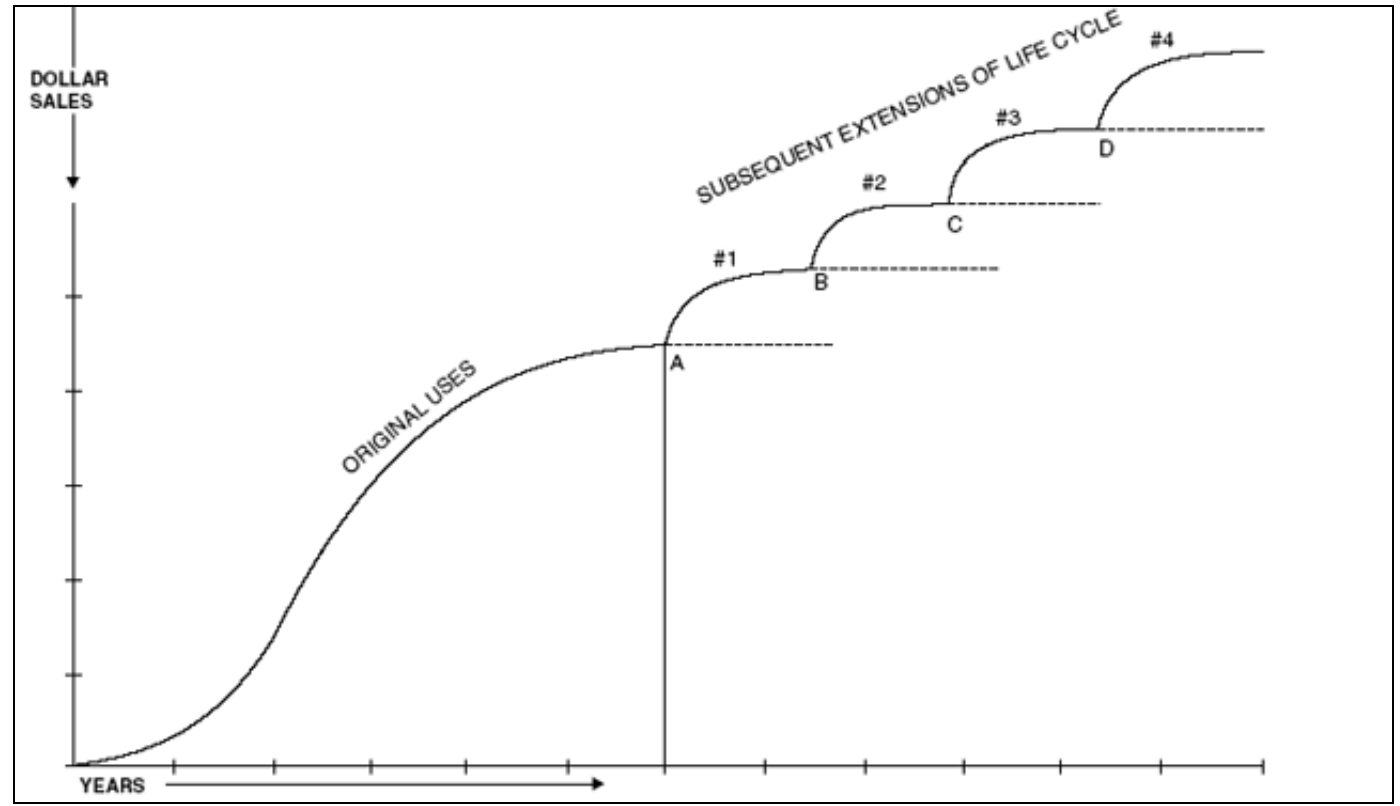

Figure 2. Exploiting the stages of the product life cycle (Levitt, 2017).

The figure is an illustration of stages that most manufacturing products undergo. However, the figure above brings out a different scenario which is an outcome of the networked manufacturing system. Based on the figure, the product experiences decline at point A but the sales are expanded from point A to B. The use of networked manufacturing systems can be vital in making appropriate decisions that are so helpful in decision making in order to keep the product remain competitive in the market (Kumar \& Putnik, 2014). Jell-O is a good example of companies which have managed to stretch the life cycle of the products. Scotch tape is the product under consideration. The excellent marketing strategy and the soundness of the concept of its product gave the company ascending sales and curves from the start. However, several years down the line, the curve began to flatten. The company made a decision of perfecting the product and once again the product gained its market acceptance.

The use of the system in a product's life cycle can help a company to make the following decision that might be helpful in the decline stage of a product. 
It can be useful in promoting more frequent use apart from other current uses by creating more use of the product.

It can be helpful in creating new users through market expansion among other strategic decisions (Kim \& Mauborgne, 1999).

The networked manufacturing system has the potential of changing the landscape of manufacturing industry. They are tools for analysis to enable intelligent and most informed decision making given the sheer volume of data that companies generate from their operations (Thomas, 2014). The knowledge about the product can be accessed easily, summarized and analyzed to provide better decision making. The system can identify areas where losses are likely to occur to either reduce or eliminate the losses at various stages of the product. Network manufacturing systems have performance metric module that is vital in the review of standard times as well as the reasons for deviations. Most studies argue that such systems have the potential of guiding strategic decisions at the business level. Various researchers also point out that the systems improve the overall performance by identifying areas that give the greatest return on investment at various stages of product life cycle.

\begin{tabular}{|c|c|c|c|c|}
\hline \multicolumn{5}{|c|}{ Networked manufacturing system } \\
\hline $\begin{array}{c}\text { Better decision } \\
\text { making }\end{array}$ & Problem solving & $\begin{array}{c}\text { Potential of market growth } \\
\text { and industrial automation }\end{array}$ & $\begin{array}{c}\text { Quality management } \\
\text { in a product life cycle }\end{array}$ & $\begin{array}{c}\text { Real-time monitoring } \\
\text { and control at various } \\
\text { life stages }\end{array}$ \\
\hline
\end{tabular}

\section{Discussion/Conclusion}

Based on the results of the study, networked manufacturing systems can act as one of the strategies for extending the product life cycle (Chitale \& Gupta, 2005). Companies whose products are in decline can embrace the strategy to save their product by increasing sales and outdoing the competition. The networked systems are linked by heterogeneous networks. Thus the process of decision making is spread among individual control agents depending on the common international goal. It implies that companies make collaborative decisions which ensure the best choices are made out of all alternatives. Networked manufacturing systems involve monitoring and both lowering level control and supervisory control (Subrahmanian, Rachuri, Fenves, Foufou, \& Sriram, 2005). The systems can be joined with resource management to provide control strategies in product life cycle. Various stages of the product lifecycle especially the decline stage can be rectified by the use of networked manufacturing systems. Most companies have information model of defining products requirements and behaviors of product components. They can, therefore, monitor and control their different products at different stages of product life cycle. A networked manufacturing system can be an important toll for the business task.

In conclusion, companies can, therefore, address the challenge of coping with quality management in a product life cycle by the use of networked manufacturing systems. Just as mentioned earlier, carrying out manufacturing process without managing quality in an integrated manner in the entire life cycle of a product can be very costly to companies. The performance of a company' product can be optimized by the use of networked manufacturing systems. 


\section{References}

Brookins, M. (2017). How to maintain strategies in a decline stage. Smallbusiness.chron.com. Retrieved 11 February 2017, from http://smallbusiness.chron.com/maintain-strategy-decline-stage-26080.html

Chitale, A., \& Gupta, R. (2005). Product design and manufacturing (1st ed.). New Delhi: Prentice-Hall of India.

Dorfman, R. (2006). Theory of production | economics. Encyclopedia Britannica. Retrieved 10 February 2017, from https://www.britannica.com/topic/theory-of-production

Jiang, X. Y., Zhao, K., Zhang, Y., \& Wang, W. S. (2008). Research on product lifecycle oriented quality management system based on networked manufacturing. IEEE Xplore, 1. Retrieved from http://ieeexplore.ieee.org/document/4680070/

Kim, C., \& Mauborgne, R. (1999). Creating new market space. Harvard Business Review. Retrieved 11 February 2017, from https://hbr.org/1999/01/creating-new-market-space

Kumar, V., \& Putnik, G. (2014). Resource scalabilities in networked manufacturing systems: Social network analysis based $\begin{array}{lllll}\text { approaches. } & \text { Springerlink, } & 1, & \text { Retrieved from }\end{array}$ http://link.springer.com/referenceworkentry/10.1007/978-1-4471-4976-7_116-1

Levitt, T. (2017). Exploit the product life cycle. Harvard Business Review. Retrieved 10 February 2017, from https://hbr.org/1965/11/exploit-the-product-life-cycle

McFarlane, D., \& Sarma, S. (2002). The intelligent product in manufacturing control. Journal of EAIA, 1(1). Retrieved from https://pdfs.semanticscholar.org/1e6a/b9815d1cd0e4f08719773ddc88f0f9c6c2cc.pdf

Meyer, M. (2013). Network theory approaches for robustness measurement in a dynamic manufacturing system. Researchgate, 1(1). Retrieved from https://www.researchgate.net/publication/275958840_A_network_theory_approach_for_robustness_measurement_in_dynam ic_manufacturing_systems

Product Life Cycle Stages. (2017). Productlifecyclestages.com. Retrieved 11 February 2017, from http://productlifecyclestages.com/

Quality Lifecycle $\quad$ Management. $\quad$ (2011). $\quad$ PTC, $\quad 1 . \quad$ Retrieved from http://www.ptc.com/ /media/Files/PDFs/PLM/Quality-Lifecycle-Management.pdf?la=en

Subrahmanian, E., Rachuri, S., Fenves, S., Foufou, S., \& Sriram, R. (2005). Product lifecycle management support: A challenge in supporting product designs and manufacturing in a networked economies. International Journal of Product Lifecycle Management, 1(1), 4. Retrieved from http://dx.doi.org/10.1504/ijplm.2005.007342

Thomas, F. (2014). Strategic management of global manufacturing networks, $1 . \quad$ Retrieved from http://file:///C:/Users/n/Downloads/9783642341847-c2.pdf

Zheng, X., \& Chen, D. (2005). Secure strategy for networked manufacturing system. Systems, Man and Cybernetics, 1. Retrieved from http://ieeexplore.ieee.org/document/1401195/

Zhuang, Q., \& Zhang, D. (2010). Wireless sensor network for networked manufacturing system, 1. Retrieved from http://www.intechopen.com/books/factory-automation/wireless-sensor-networks-for-networked-manufacturing-systems 